\title{
Performance of Gps Telemetry Collars for Red Deer Cervus Elaphus in Rugged Alpine Terrain Under Controlled and Free-living Conditions
}

Author(s): Barbara Zweifel-Schielly and Werner Suter

Source: Wildlife Biology, 13(3):299-312.

Published By: Nordic Board for Wildlife Research

DOI: http://dx.doi.org/10.2981/0909-6396(2007)13[299:POGTCF]2.0.CO;2

URL: http://www.bioone.org/doi/

full/10.2981/0909-6396\%282007\%2913\%5B299\%3APOGTCF\%5D2.0.CO $\% 3 \mathrm{~B} 2$

BioOne (www.bioone.org) is a nonprofit, online aggregation of core research in the biological, ecological, and environmental sciences. BioOne provides a sustainable online platform for over 170 journals and books published by nonprofit societies, associations, museums, institutions, and presses.

Your use of this PDF, the BioOne Web site, and all posted and associated content indicates your acceptance of BioOne's Terms of Use, available at www.bioone.org/page/terms_of_use.

Usage of BioOne content is strictly limited to personal, educational, and non-commercial use. Commercial inquiries or rights and permissions requests should be directed to the individual publisher as copy right holder. 


\title{
Performance of GPS telemetry collars for red deer Cervus elaphus in rugged Alpine terrain under controlled and free-living conditions
}

\author{
Barbara Zweifel-Schielly \& Werner Suter
}

Zweifel-Schielly, B. \& Suter, W. 2007: Performance of GPS telemetry collars for red deer Cervus elaphus in rugged Alpine terrain under controlled and free-living conditions. - Wildl. Biol. 13: 299-312.

In mountainous terrain, performance of VHF telemetry is often impaired by long distances between observer and animal, and by reflections of radio signals. GPS telemetry should be less affected by such constraints, but its performance has not been sufficiently tested in areas of rugged topography. We studied how current GPS telemetry deployed on red deer Cervus elaphus performs in the strong topographic relief of a rugged Alpine landscape. We examined the influence of topography, vegetation and red deer activity on GPS performance, assessed the accuracy of $2 \mathrm{D}$ positions of red deer and compared differences in GPS performance between collars in trials and collars fitted to deer. GPS performance was characterised by consistently high position acquisition rates (PAR), but a relatively low proportion of $3 \mathrm{D}$ positions compared to smoother terrain. The proportion of $3 \mathrm{D}$ positions was lower in forest than in open land but within forest different vegetation structures had only a weak influence. For collars fitted to red deer, we found that $>70 \%$ of the positions were either 3D positions or accurate 2D positions. The collars produced higher PAR and proportions of 3D positions in the trials than when they were fitted to red deer, probably reflecting an effect of red deer behaviour. We also observed better performance of collars on red deer during night than during daytime, because animals were more active at night where they more often occurred in open land. An effect of season on the proportion of $3 \mathrm{D}$ positions was found in collars fitted to red deer, but not in the trials, and may be interpreted as a secondary effect produced by seasonal differences in habitat selection by red deer. The fact that PAR was not affected more strongly by the rugged mountainous relief probably reflects the recent progress achieved in GPS technology, whereas the comparatively low proportion of $3 \mathrm{D}$ positions illustrates that the probability of four satellites being available at any one time is still constrained by topography.

Key words: Alps, Cervus elaphus, Global positioning system, GPS performance, mountainous topography, red deer, vegetation characteristics

Barbara Zweifel-Schielly*, Swiss Federal Research Institute WSL, Wildlife Ecology, Zuercherstrasse 111, 8903 Birmensdorf, Switzerland, and ETH Zürich, Nature and Landscape Conservation, Universitätsstrasse 22,8092 Zürich, Switzerland-e-mail: jueba@bluewin.ch

Werner Suter, Swiss Federal Research Institute WSL, Wildlife Ecology, Zuercherstrasse 111,8903 Birmensdorf, Switzerland-e-mail: werner.suter@, wsl.ch

*Present address: Zettess energy and environment, Zaunplatz 4, 8750 Glarus, Switzerland 
Corresponding author: Werner Suter

Received 30 April 2005, accepted 7 May 2006

Associate Editor: John P. Ball

Telemetry systems built on the Global Positioning System (GPS) technique were developed during the 1990s, and since then GPS performance has steadily improved. Advancements include more channels and better search algorithms in GPS receivers, and the possibility to obtain more accurate locations after the Selective Availability (SA) was disabled in May 2000. Today, GPS telemetry systems have the potential to collect large amounts of locations which can be obtained during day and night under any weather and terrain conditions. Many of the problems associated with traditional VHF telemetry (VHF = very high frequency) are thus overcome (e.g. Springer 1979, Mills \& Knowlton 1989, White \& Garrott 1990, Beyer \& Haufler 1994, Rodgers et al. 1996, Girard et al. 2002).

However, whether the full potential can be utilised depends, among other things, on the number and constellation of visible satellites. Three classes of position accuracy are possible: 1) $>3$ visible satellites produce a 3-dimensional (3D) position, 2) three visible satellites produce a 2-dimensional (2D) position and 3) $<3$ visible satellites do not allow a position to be taken, which reduces position acquisition rate (PAR). On average, 3D positions are more accurate than 2D positions (Edenius 1997, Dussault et al. 2001, Janeau et al. 2001a). The number of visible satellites, and therefore PAR or proportion of $3 \mathrm{D}$ positions, can be affected by physical obstacles between the GPS collar and the satellites. Frequency and type of obstacles are related to habitat and topography, and so are PAR and proportion of 3D positions. Several studies worldwide have identified forest in general, forest type, canopy cover or tree characteristics, such as basal area or height, as affecting position acquisition rate (Rempel et al. 1995, Moen et al. 1996, Rumble \& Lindzey 2000, D'Eon et al. 2002), proportion of 3D positions (Rempel \& Rodgers 1997, Gamo et al. 2000), or both (e.g. Edenius 1997, Dussault et al. 1999, Janeau et al. 2001b). A few studies found no effect of vegetation characteristics on GPS performance (Bowman et al. 2000, Biggs et al. 2001).

We know of 19 published studies (by late 2005) that investigate GPS performance under different environmental conditions. Many of the results may no longer be relevant, because 15 of these studies were conducted before the SA was disabled in May 2000, and several of them used GPS receivers with $<12$ channels which is the standard today. Especially in rugged mountainous terrain GPS performance may now be superior to traditional VHF telemetry. VHF telemetry suffers in difficult terrain from lower performance due to often long distances between observer and animal, and from radio signals being reflected by cliffs and mountainsides (Garrott et al. 1986, Haller et al. 2001).

However, the effect of rugged topography on reducing the number of visible satellites has not been sufficiently tested. So far, most of the earlier studies have been conducted in regions with little topographic relief (D'Eon et al. 2002). We know of four published studies on GPS performance in mountainous regions, all from Canada and USA (Gamo et al. 2000, Rumble \& Lindzey 2000, D'Eon et al. 2002, Frair et al. 2004), but none was in terrain nearly as rugged as the central Alps. Nevertheless, these studies admitted to constraints in GPS performance set by topographic characteristics affecting the visible sky and thus, the number of visible satellites. While it may seem obvious that in mountainous areas the proportion of 2D positions will be higher and PAR will be lower than in (flat) lowlands, the additional problem that 2D positions can also be much more inaccurate in mountainous topography is not generally recognised. This is because the telemetry system's programme substitutes the missing information from the fourth satellite by an estimation of the altitude of the GPS collar (Wells et al. 1986). Most GPS collar brands use the altitude of the last stored $3 \mathrm{D}$ position. The more this value differs from the actual altitude, the less accurate the 2D position will be (Moen et al. 1997, Dussault et al. 2001). The problem is more prevalent for animals that make quick altitudinal movements than for less vagile species.

In a number of studies, GPS collar performance was assessed either in trials (collars hand-held by the researchers or deployed at known locations) or after collars had been fitted to free-ranging animals. 
Few studies have simultaneously compared performance in both situations, and although in two studies there was no difference (Rempel et al. 1995, Moen et al. 1996), others have reported that collars fitted to animals performed less well (Edenius 1997, Dussault et al. 1999, 2001, D'Eon et al. 2002, 2003). It has been suggested that certain types of behaviour, such as bedding or moving, could reduce PAR or proportion of 3D positions (Moen et al. 1996, Edenius 1997, Bowman et al. 2000, Rumble et al. 2001). Though behaviour is expected to be related to habitat, none of the studies have investigated whether differences in performance between collars in trials and after having been fitted to animals were associated with habitat. Such data will, however, be needed for identifying possible bias in habitat selection studies. Of the six studies known to us to contain data on GPS collar performance from Cervus elaphus (European red deer: Fielitz et al. 1996, Janeau et al. 2001b, Licoppe \& Lievens 2001; American elk: Biggs et al. 2001, Lindzey et al. 2001, Rumble et al. 2001), only two investigated performance with respect to habitat use (Biggs et al. 2001) or behaviour (Rumble et al. 2001).

We investigated how current GPS technology for telemetry studies of red deer performs in the strong topographic relief of a rugged Alpine landscape. Our objectives were: 1) to examine the influence of topographical and vegetation characteristics, and of general red deer activity on GPS performance; 2) to assess the accuracy of 2D positions of red deer; and 3) to compare differences in GPS performance between trials with controlled conditions and after collars had been fitted to wild red deer, with the purpose of identifying possible biases inherent in red deer positions obtained using GPS telemetry. As our data do not allow us to create behavioural-based correction factors, we use an indirect approach and look at how general activity patterns, home-range composition and home-range use can affect GPS performance.

\section{Study area}

Our study area (ca $250 \mathrm{~km}^{2}$ ) is located on the northern flank of the Swiss Alps in the canton of Glarus, east-central Switzerland $\left(47^{\circ} 00^{\prime}, 09^{\circ} 07^{\prime}\right)$. The area contains two narrow main valleys and several small side valleys. The terrain is steep and rocky with gradients of $>100^{\circ}$ and slope aspects within 1$360^{\circ}$. Elevations range within $470-2,060 \mathrm{~m}$ a.s.1. at the highest test sites and red deer positions, although mountain peaks reach up to 3,614 $\mathrm{m}$ a.s.1.
The climate shows both oceanic and continental influence, and varies strongly with altitude. At the valley bottom, mean long-term climatic variables are: a) monthly sum of precipitation: $86-177 \mathrm{~mm}$ with an annual sum of $1,416 \mathrm{~mm}, \mathrm{~b}$ ) monthly mean temperature: $-1-+17^{\circ} \mathrm{C}$ with an annual mean temperature of $+8^{\circ} \mathrm{C}$ and c) monthly duration of sunshine: 51-172 hours with an annual sum of 1,265 hours (MeteoSwiss, unpubl. data). Settlements are limited to the narrow valley bottom and cover about $3 \%$ of the total area. About one third of the area is farmland, mostly grassland either at the valley bottom (being cut several times a year) or above the timber line (i.e. alpine pastures or hay meadows cut once a year). Another third consists of forest and subalpine scrubland, mainly on mountainsides, whereas the rest is classified as unproductive area (Swiss Federal Statistical Office, unpubl. data). Forests situated within about 400-900 m a.s.l. are mainly deciduous, dominated by beech Fagus silvatica and, in a few cases, by sycamore maple Acer pseudoplatanus. Within about 9001,400 $\mathrm{m}$ a.s.1., stands are mixed with beech, silver fir Abies alba and Norway spruce Picea abies, whereas coniferous forest (mainly Norway spruce and some silver fir) is the main vegetation within 1,400-1,900 $\mathrm{m}$ a.s.1. Locally, along the timberline, there is a belt of green alder shrubbery Alnus incana or dwarf mountain pine Pinus mugo (Marti et al. 1997). Forest is mostly a small-scale mosaic of the full range of age classes (young-growth to oldgrowth) and canopy closure varying from $0 \%$ in the many small clear-cuts and natural openings, e.g. wind-throw areas and stream gullies, to $100 \%$ in dense, younger stands.

\section{Material and methods}

Our aims were threefold: 1) to assess the accuracy of $3 \mathrm{D}$ positions and 'optimal' 2D positions (i.e. the $2 \mathrm{D}$ positions that did not differ in elevation from the last recorded 3D position, see below) obtained from a stationary GPS collar (positioning trials, first part); 2) to analyse GPS performance (PAR, proportion of $3 \mathrm{D}$ positions) under various habitat conditions by means of a hand-held collar (positioning trials, second part); and 3) to investigate GPS performance (PAR, proportion of 3D and of accurate 2D positions) under 'real' conditions, i.e. of collars fitted to free-ranging red deer in a rugged mountainous landscape. 


\section{Positioning trials}

We used non-differentially corrected 12-channel GPS collars (GPS Simplex ${ }^{\mathrm{TM}}$ ) manufactured by TVP Positioning AB (Televilt, Lindesberg, Sweden). First, we tested a stationary collar for locational accuracy of 3D and 2D positions during five days in February 2003. The collar was mounted on a small platform about one metre above ground under open sky at a location with known geographic coordinates. A positioning attempt was started every fourth minute according to a programmed schedule, with time to search for satellites set at 180 seconds, the same duration as was later used in collars fitted to red deer.

Second, we tested the collar on the move through habitats differing in topography and vegetation composition and structure. The investigator carried the collar on the shoulder about $1.50 \mathrm{~m}$ above ground to mimic conditions of a collar fitted to a red deer. Different habitat types were traversed on a predetermined route that was kept as straight as possible. Routes were walked during daytime in 10 different trial areas, which later were also regularly used by collared red deer, during 11 days before leaf fall (September-October 2002) and during four days after leaf fall (November-December 2002). On each day and in each trial area positioning attempts were made in the whole range of habitats considered in the study. We did this to avoid possible biases which might have arisen from satellite visibility varying across days and trial areas. As in the first trial, positioning attempts were started every fourth minute, and search duration was set at 180 seconds. During positioning attempts the investigator stopped walking. Each location was sought to be recorded only once. The mean time lapse between two consecutive attempts was in fact longer than four minutes; i.e. when only sequential pairs in the same main habitat type (forest and open land) were considered, and occasional long pauses by the investigator were also taken into account (mean time lapse in forest: 6.9 minutes; SD = 7.1 minutes; mean time lapse in open land: 28.9 minutes; SD $=40.6$ minutes). Possible concerns about autocorrelation in the outcomes of consecutive positioning attempts, in the sense that they may have been influenced by similar satellite configurations, can be dispelled in the case of open ground positions by the time lapse alone. In the case of locations within forest, the outcomes of consecutive positioning attempts were similar to the overall probability (94.2 and $93.1 \%$, respectively, for a position being acquired at all, and 77.4 and $71.6 \%$, respectively, for a 2D-position), so autocorrelation was not a serious problem.

During each positioning attempt we recorded the following habitat parameters within a radius of approximately $10 \mathrm{~m}$ : habitat type (forest, open land), altitude (measured using an altimeter), slope $\left(^{\circ}\right)$ and aspect (north: $271-90^{\circ}$, south: $91-270^{\circ}$; both determined subsequently in Geographic Information System GIS ESRI ArcView 3.2, GIS layers with a resolution of $25 \mathrm{~m}$ ), proportion of conifers (estimated as $>80 \%$ of the trees are conifers, mixed $=$ $20-80 \%$ of the trees are conifers and deciduous trees respectively or $>80 \%$ of the trees are deciduous trees), forest age class (estimated as young-growth with a DBH of 8-20 cm, even-aged old-growth with a DBH of $>20 \mathrm{~cm}$ or uneven-aged) and canopy closure (estimated as closed $=$ crowns affected by each other or open $=$ crowns not affected). To account for differences in the mean availability of satellites produced by the area of sky available to a GPS collar (i.e. sky not obstructed by the main topography, a value generally higher on mountain tops than in narrow valleys), a variable 'visible sky' has been used in recent studies (Gamo et al. 2000, Rumble \& Lindzey 2000, D'Eon et al. 2002, Frair et al. 2004). Because all positions taken in our study were taken from the bottom or flank of evenly sloped valleys with similar opening angles, and none were taken from ridges or mountain tops, 'visible sky' was not expected to vary strongly and we did not use this variable. However, because the opening angle as seen from a given location on the slopes increases with distance from the valley bottom, we included altitude instead as a variable in the analysis.

We used $\chi^{2}$ Crosstab tests (likelihood ratio) to detect differences in PAR and the proportion of 3D positions between forest and open land, and between seasons (before and after leaf fall). For each habitat type (forest and open land) we used logistic multiple regression (backward stepwise) to model the relationships between habitat parameters and the dependent variables PAR or 3D positions, which were both treated as binary variables. We considered candidate models to include all possible combinations of non-correlated variables (Pearson $\mathrm{r}<0.5$ ) and appropriate interaction terms. Therefore, potential covariates in open land were altitude, slope and aspect, and in forest additionally forest age class and canopy closure. Dichotomous variables were treated as dummy variables. For 
processing categorical covariates ( $>2$ categories), we used contrast deviation and the last category as reference. Akaike's information criterion $(\mathrm{AIC}=$ $-2 \mathrm{LL}+2(\mathrm{k}+1), \mathrm{k}=$ number of regression variables) was used to identify the model that best explained our data (Burnham \& Anderson 2002). We assessed model fit using Hosmer-Lemeshow goodness-of-fit statistic (Hosmer \& Lemeshow 2000). For all analyses, significance level was $\alpha=0.05$.

\section{Positions of red deer}

In the two winters of 2001/02 and 2002/03, we immobilised 18 red deer (nine females and nine males) by darting them with a Xylazin-Zoletil-Mixture ('Vienna Mixture'). All animals were equipped with non-differentially corrected 12-channel-GPS Simplex $^{\text {TM }}$ collars (Televilt, Sweden). The GPS collars were programmed to make a positioning attempt every second hour on two days per week during two years. Latitude, longitude, date, time and dilution of precision (DOP) of all successful positions were stored on the GPS collars. Each GPS unit was equipped with a VHF transmitter, which was used both as traditional beaconing and as a radio link for transferring the coded GPS data to a remote receiver (data-logger RX900 ${ }^{\mathrm{TM}}$, Televilt, Sweden) once per month. Data were downloaded to a computer in which geographic coordinates were transformed into Swiss national coordinates using software by Regine Fankhauser.

VHF signals were also used to transmit activity data recorded by an activity sensor that was built into the collars. On two days per month, three diurnal and three nocturnal activity measurements were made per individual. Measurements lasted for two minutes and there had to be at least two hours between two consecutive measurements. If a measurement contained at least one minute of active behaviour, the red deer was classified as active, otherwise as inactive. Because positioning and activity recording had to be at different times, it was not possible to relate GPS collar performance directly to red deer activity. It was, however, possible to compare seasonal differences in diurnal and nocturnal activity and habitat use with respective patterns of GPS collar performance.

As measurements of GPS collar performance, we determined PAR, proportion of $3 \mathrm{D}$ and accurate 2D positions, activity and open land use for each individual and season, and (except with accurate 2D positions) for day (during 08:00-14:00 GMT) and night (during 20:00-02:00 GMT). Open land use was expressed as the ratio of successful positions in open land to all successful positions. A 2D position was defined as accurate, if its altitude did not differ more than $150 \mathrm{~m}$ from the last stored 3D position. Moen et al. (1997) had found that with this difference, $95 \%$ of $2 \mathrm{D}$ positions were within $187 \mathrm{~m}$ of the true location and median locational error was $72 \mathrm{~m}$. We considered this accuracy sufficient in view of the spatial scale, the resolution of habitat maps and the number of positions per individual red deer used in our planned habitat selection study. While Moen et al. (1997) obtained their data using collars working in differential mode, but before removal of SA, our equipment was non-differential, but we had the advantage of disabled SA. This should have more than compensated for the lower performance of non-differential equipment (Janeau et al. 2001b and results below).

To analyse PAR in relation to habitat parameters, GPS positions were transferred to a GIS (using ESRI ArcView 3.2). For each individual and season, we determined separate home ranges with the 95\% minimum convex polygon method, using extension Animal movement (Hooge \& Eichenlaub 1997). We took existing grid maps (with a resolution of $25 \mathrm{~m}$ ) in GIS to calculate the percentage area of a number of habitat categories for each home range. We could use most of the habitat parameters already chosen for trial data and assigned them two categories each (altitude: low $\leq 1,200 \mathrm{~m}$, high $>$ $1,200 \mathrm{~m}$; slope: plain $\leq 30^{\circ}$, steep $>30^{\circ}$; aspect: north $271-90^{\circ}$, south $91-270^{\circ}$; see Table 3 ).

We also calculated the proportion of 3D and accurate $2 \mathrm{D}$ positions per habitat category. For some habitat parameters (habitat type, altitude, slope and aspect) that were available as grid maps (with a resolution $25 \mathrm{~m}$ ) in GIS, proportions were calculated with all positions of an individual in one season. For three habitat parameters (i.e. proportion of conifers, forest age class and canopy closure; categories see Positioning trials) data did not exist as GIS layers but only as randomly distributed sampling plots (radius $=75 \mathrm{~m}$ ). For these parameters, proportions were calculated for each plot category with the positions of all red deer individuals in the respective plot category, for winter and spring-summer.

We used Friedman tests to detect differences in PAR, proportions of $3 \mathrm{D}$ positions, red deer activity and open land use between seasons, and Wilcoxon signed-rank tests for differences between day and night, and also for pair-wise comparisons (with 
Bonferroni adjusted probabilities) when Friedman tests were significant (significance level $\alpha=0.05$ ). Depending on data type (continuous GIS layers, sampling plots), we used Wilcoxon signed-rank tests or $\chi^{2}$ crosstab tests (likelihood ratio) to explore differences in proportions of 3D and accurate 2D positions between habitat categories. When results of the $\chi^{2}$ crosstab tests were significant, we made pair-wise comparisons with Bonferroni adjusted probabilities. Linear regression was applied to relate PAR to habitat categories and seasonal activity. All analyses were conducted using the statistical software SPSS ${ }^{\circledR}$ (release 11.0.1, SPSS Inc., Chicago, Illinois, USA).

\section{Results}

\section{Positioning trials}

To determine locational accuracy of a stationary collar, we took 377 positions (3D: $N=126,2 \mathrm{D}$ : $\mathrm{N}=251$ ). Locational accuracy in 3D mode was within $6.7 \mathrm{~m}$ in $50 \%$ and within $19.8 \mathrm{~m}$ in $95 \%$ of positions (mean $=7.9 \mathrm{~m}, \mathrm{SD}=5.7 \mathrm{~m}$; range: 2.8 $19.9 \mathrm{~m}$ ), and for 2D positions $10.0 \mathrm{~m}$ and $40.2 \mathrm{~m}$, respectively $($ mean $=13.9, \mathrm{SD}=14.5 \mathrm{~m}$; range: 2.8 $133.3 \mathrm{~m}$; error $>50 \mathrm{~m}$ in only five positions).

From the GPS collar carried on the shoulder by the investigator across different habitats, 697 positioning attempts were made in 10 sampling areas. Overall PAR was $93.2 \%$, and the proportion of 3D positions was $36.4 \%$. In forest, both PAR $\left(\chi^{2}=\right.$ $6.679, \mathrm{P}=0.022)$ and the proportion of $3 \mathrm{D}$ positions $\left(\chi^{2}=70.333, \mathrm{P}<0.001\right.$; see Fig. 5 left side $)$ were smaller than in open land. However, even in forest PAR exceeded $90 \%$, and the small difference, though significant, was accordingly weak $(\mathrm{Phi}=$ 0.085).

In both open land and forest, none of the tested habitat parameters and interactions was found to affect PAR in the highest ranked AIC-selected regression models. The proportion of $3 \mathrm{D}$ positions was also not affected by the investigated variables (topographical parameters) in open land. In forest, the highest ranked model included age class and canopy closure without interactions, but the model explained little of the total variance in the probability of obtaining a $3 \mathrm{D}$ position (Nagelkerke $\mathrm{R}^{2}=$ 0.058; Table 1). The proportion of $3 \mathrm{D}$ positions was lower in closed than in open forest, and it decreased from young-growth to old-growth to uneven-aged forest stands (Fig. 1).

To test for possible differences in collar performance before and after leaf fall, we compared the data from closed uneven-aged stands of deciduous trees. We detected no effect, neither for PAR $\left(\chi^{2}=\right.$ $0.429, \mathrm{P}=0.607)$ nor for proportion of $3 \mathrm{D}$ positions $\left(\chi^{2}=1.032, \mathrm{P}=0.353\right)$.

\section{Positions of red deer}

A manufacturing error produced erratic failures in several GPS collars, with both GPS units and VHF transmitters involved, thus a considerable percentage of the GPS positions and activity measurements were lost. The final data set allowed calculation of PAR, proportion of $3 \mathrm{D}$ positions, home ranges and open land use for 10 of the 18 red deer for winter (January-March), spring (April-June) and summer (July-August) in 2002 (one individual) or 2003 (nine individuals). The numbers of positions obtained from the 10 red deer were quite balanced, and ranged within 74-218 in winter, 113-231 in spring and 105150 (one individual with 59 positions) in summer leading to a total of 4,206 positions. Depending on transmitter functioning, the number of red deer per season that produced sufficient activity data $(\geq 10$ measurements/season, day or night) varied between nine and 13 . The final sum of activity measurements used in the analysis was 1,098.

Individual PAR ranged within 54.2-83.3\%, showing no temporal trend, as seasonal means remained nearly constant at ca $70 \%$ (range: 67.9$71.8 \%$; see Fig. 5). The individual proportion of 3D positions was relatively low, ranging within 4.4-48.9\%. Seasonal means were similar in winter $(32.3 \%)$ and spring $(32.4 \%)$, but were lower in sum-

Table 1. Highest-ranked AIC-selected logistic regression model for predicting the probability of acquiring a $3 \mathrm{D}$ position $(\mathrm{N}=409)$ in forest during the trials in the canton of Glarus, Switzerland, during September-October 2002 (Nagelkerke $\mathrm{R}^{2}=0.058$ ). The reference category for age class was old-growth.

\begin{tabular}{|c|c|c|c|c|c|c|}
\hline Variable & Category & $\mathrm{B}$ & SE & Wald & $\mathrm{P}$ & $\operatorname{Exp}(B)$ \\
\hline Canopy closure & Closed canopy & -0.575 & 0.278 & 4.292 & 0.038 & 0.562 \\
\hline \multirow[t]{2}{*}{ Forest age class } & Young-growth & 0.489 & 0.187 & 6.818 & 0.009 & 1.630 \\
\hline & Uneven-aged & -0.435 & 0.154 & 7.970 & 0.005 & 0.647 \\
\hline Constant & & -0.576 & 0.140 & 16.808 & 0.000 & 0.562 \\
\hline
\end{tabular}



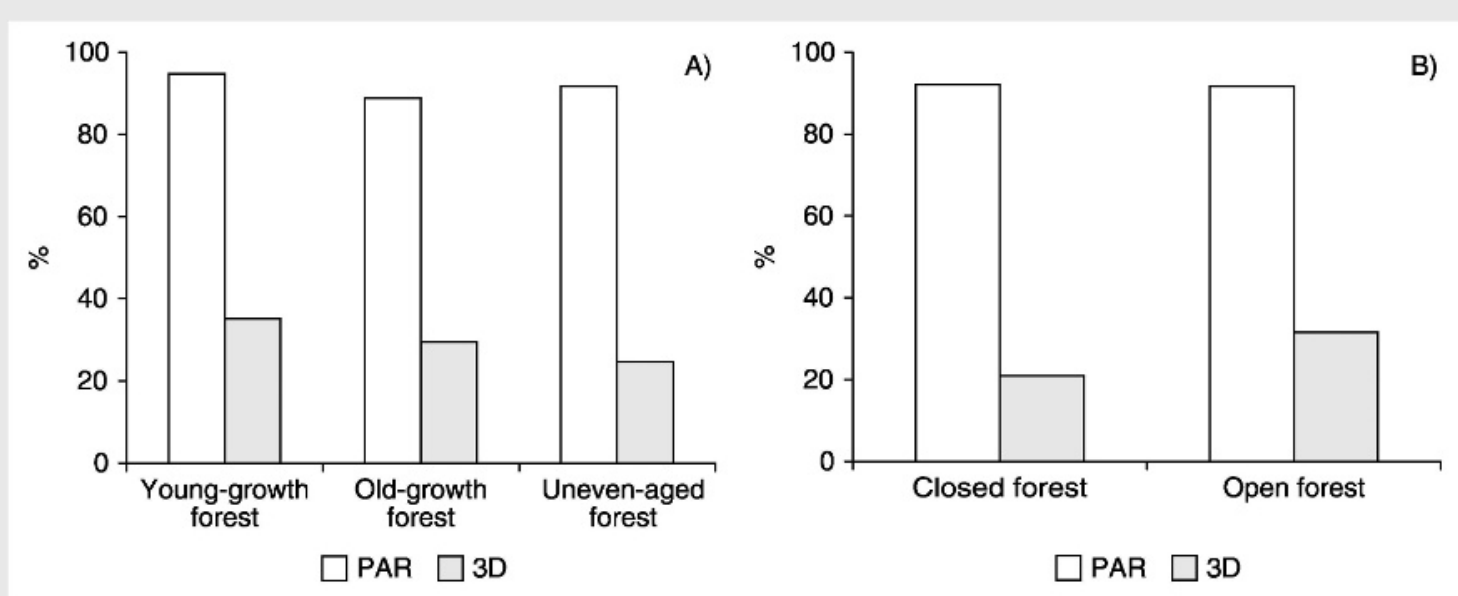

Figure 1. PAR and proportions of 3D positions in relation to forest age (A) and canopy closure (B) obtained in the trials in the canton of Glarus, Switzerland, during September-October 2002. For PAR: $N=444$ and for 3D: $N=409$.

$\operatorname{mer}\left(20.8 \% ; \chi_{2}^{2}=10.571, \mathrm{P}=0.005\right.$; Fig. 2). Open land use showed the same pattern, being highest in winter and lowest in summer $\left(\chi_{2}^{2}=10.286, \mathrm{P}=\right.$ $0.006)$, whereas red deer activity (\% measurements in which animal was classified as active) did not differ between seasons $\left(\chi_{2}^{2}=2.889, \mathrm{P}=0.236\right)$. If both $3 \mathrm{D}$ and accurate $2 \mathrm{D}$ positions were taken as sufficiently accurate measurements of red deer location, instead of only $3 \mathrm{D}$ positions, the mean seasonal proportion was 2-3 times higher than the proportion of $3 \mathrm{D}$ positions alone, and exceeded $72 \%$ in all seasons (see Fig. 2).

The association between GPS collar performance and habitat type (forest or open land) also became apparent when considered at the level of home

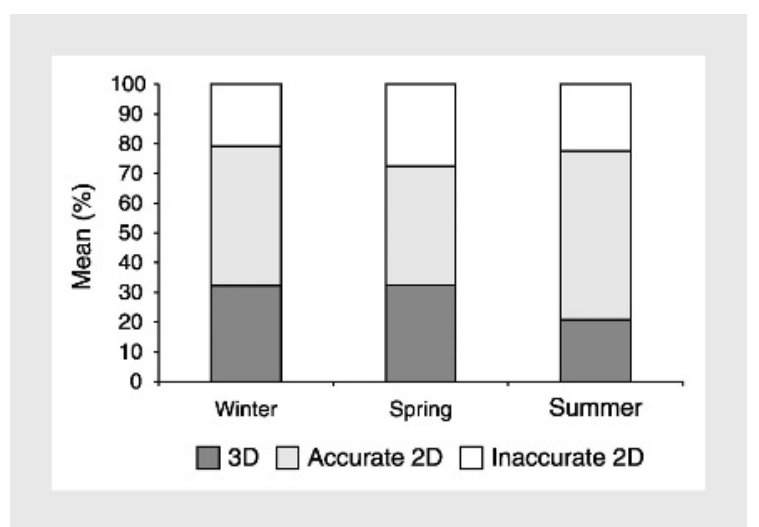

Figure 2. Proportion of accuracy classes in red deer positions in the canton of Glarus, Switzerland, during 2002-2003. For winter $\mathrm{N}=10$ deer, for spring $\mathrm{N}=9$ and for summer $\mathrm{N}=10$. See section Material and methods for the definition of accurate and inaccurate $2 \mathrm{D}$ positions. ranges. Individual PAR correlated with the percentage of open land in home ranges in summer $\left(\mathrm{R}^{2}=0.501, \mathrm{P}=0.033\right.$; Fig. 3$)$, though not at other times, nor with other habitat parameters or red deer activity in any season (see above and Material and methods section).

The proportion of accurate positions, however, was not independent of habitat. Mostly so in winter and spring, but not in summer, the proportions of 3D positions differed between the categories of all investigated habitat parameters except exposition (Table 2). The proportion of accurate $2 \mathrm{D}$ positions showed differences only for habitat type and altitude.

Differences in PAR and the proportion of 3D positions between day and night were also restricted

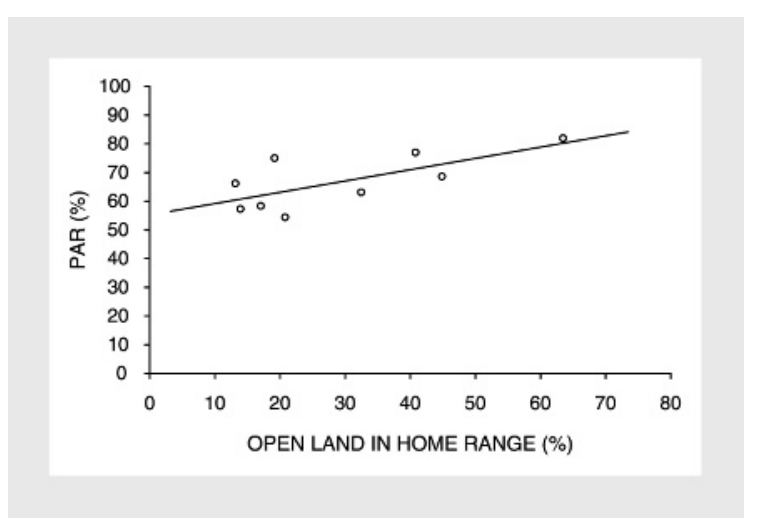

Figure 3. Positive association between PAR in individual red deer and the percentage of open land in their summer home ranges $(\mathrm{N}=9$ deer $)$ in the canton of Glarus, Switzerland, during 2002-2003. 
Table 2. Seasonal differences between habitats in the proportions of 3D and accurate 2D positions of red deer in the canton of Glarus, Switzerland, during January 2002-August 2003. For winter $N=10$, spring $N=9$ and summer $N=10$. Only significant differences are listed in the column Direction of differences.

\begin{tabular}{|c|c|c|c|c|c|}
\hline Habitat parameter & Season & Direction of differences & $\mathrm{Z}$ & $\chi^{2}$ & $\mathrm{P}$ \\
\hline \multicolumn{6}{|l|}{ 3D positions } \\
\hline \multirow[t]{2}{*}{ Habitat type } & Winter & Open land $>$ forest & -2.803 & & 0.005 \\
\hline & Spring & Open land $>$ forest & -2.666 & & 0.008 \\
\hline Altitude & Winter & Low $>$ high & -2.805 & & 0.005 \\
\hline \multirow[t]{2}{*}{ Slope } & Winter & Plain $>$ steep & -2.805 & & 0.005 \\
\hline & Spring & Plain $>$ steep & -2.668 & & 0.005 \\
\hline Proportion of conifers & Spring/summer & Mixed $>$ deciduous & & 7.956 & 0.009 \\
\hline Forest age class & Spring/summer & Young $>$ old-growth & & 8.988 & 0.003 \\
\hline Canopy closure & Autumn/winter & Open $>$ closed & & 9.168 & 0.002 \\
\hline \multicolumn{6}{|l|}{ Accurate $2 \mathrm{D}$ positions } \\
\hline \multirow[t]{2}{*}{ Habitat type } & Winter & Open land $>$ forest & -2.805 & & 0.005 \\
\hline & Spring & Open land $>$ forest & -2.255 & & 0.024 \\
\hline Altitude & Winter & Low $>$ high & -2.091 & & 0.037 \\
\hline
\end{tabular}

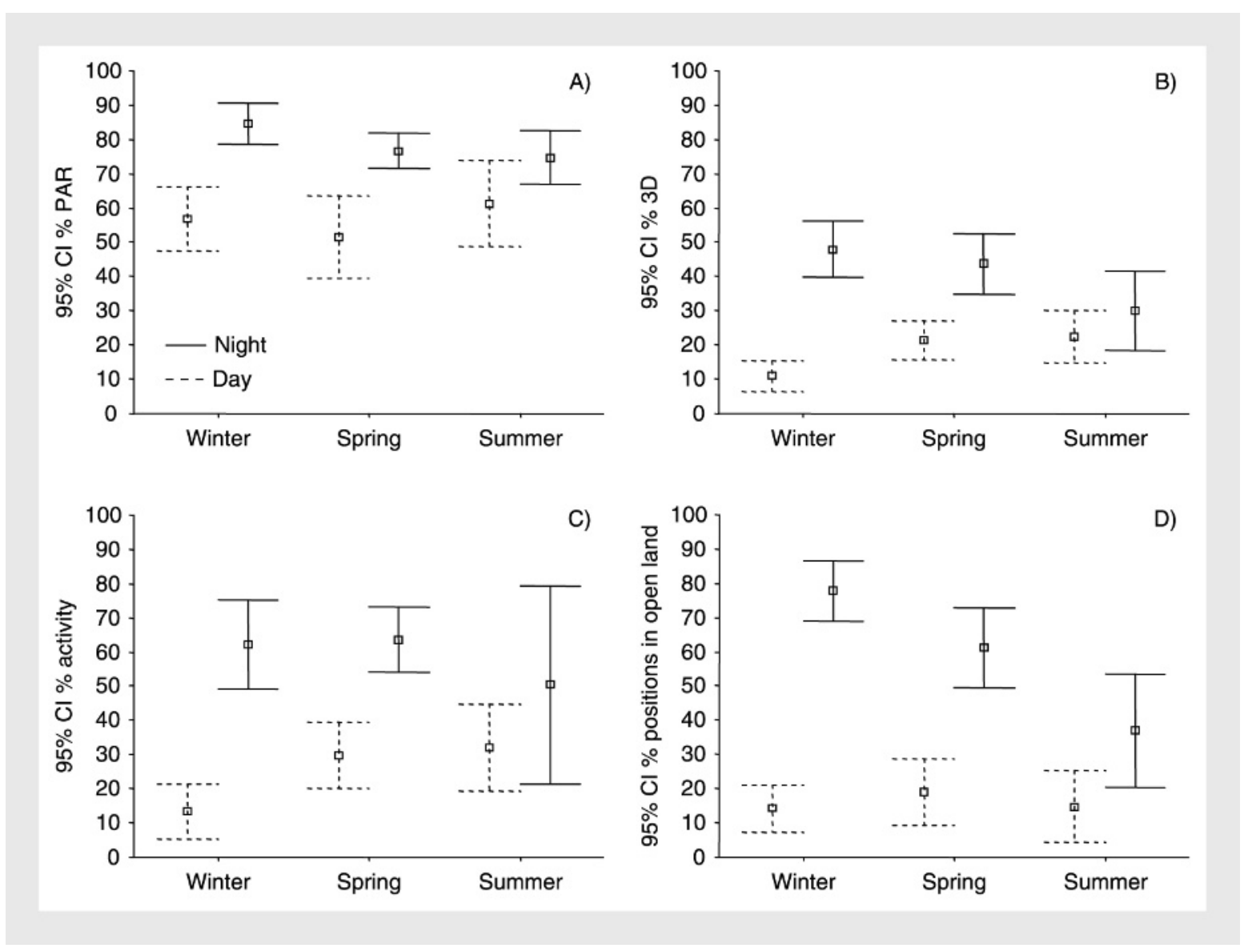

Figure 4. Seasonal differences between day and night for PAR (A), proportion of 3D positions (B), activity (C) and use of open land (D) by individual red deer in the canton of Glarus, Switzerland, during 2002-2003, given as means and 95\% confidence intervals. The sample sizes (i.e. number of individual red deer) for PAR, 3D and open land use were in winter $\mathrm{N}=10$, in $\operatorname{spring} \mathrm{N}=9$ and in summer $\mathrm{N}=10$; for activity the sample sizes were in winter $\mathrm{N}=13$, in spring $\mathrm{N}=13$ and in summer $\mathrm{N}=9$. 


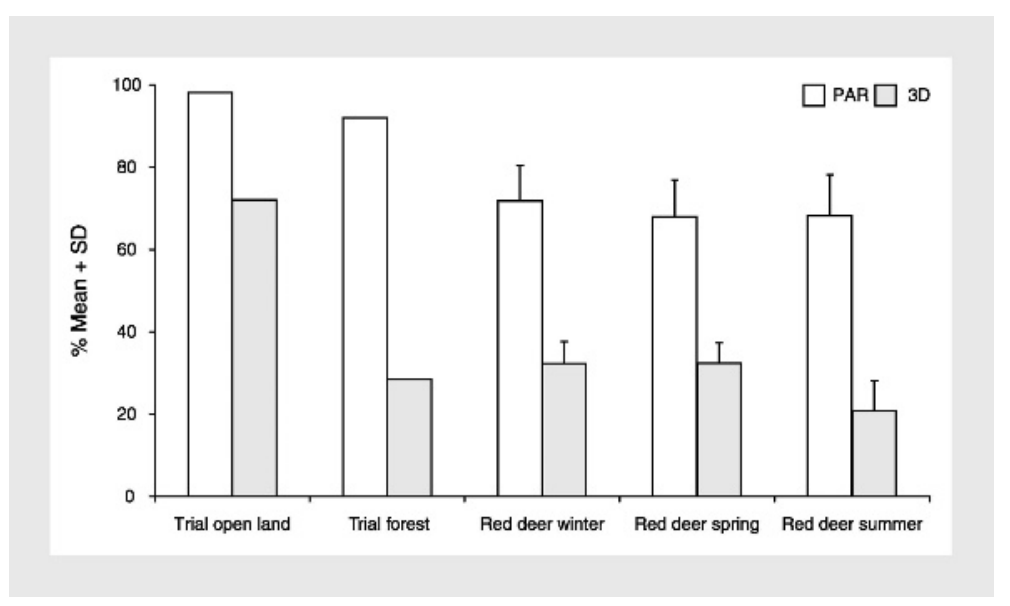

Figure 5. GPS performance of collars during trials (the two pairs of bars to the left) and when fitted to red deer (the three pairs of bars to the right) in the canton of Glarus, Switzerland, during 2002-2003. The number of positions in the trial was $\mathrm{N}=697$ and the sample sizes of red deer individuals were in winter $\mathrm{N}=10$, in spring $\mathrm{N}=9$ and in summer $\mathrm{N}=10$.

to winter and spring, although they showed the same tendency in summer (Fig. 4). PAR and 3D were lower during daytime than during night (winter PAR: $Z=-2.807, P=0.005$; winter 3D: $Z=$ $-2.803, P=0.005$; spring PAR: $Z=-2.547, P=$ 0.011 ; spring $3 \mathrm{D}: \mathrm{Z}=-2.512, \mathrm{P}=0.012$ ). PAR and $3 \mathrm{D}$ patterns corresponded to patterns of activity and habitat use (see Fig. 4), with high PAR and $3 \mathrm{D}$ values being associated with active behaviour of red deer and visits to open land at night. Red deer activity was lower during daytime than during night in winter and spring (winter: $Z=-2.934, P=0.003$; spring: $\mathrm{Z}=-3.180, \mathrm{P}=0.001$ ), whereas no differences were found in summer (see Fig. 4). Open land use was lower during daytime than during night in all seasons (winter: $\mathrm{Z}=-2.803, \mathrm{P}=0.005$; spring: $\mathrm{Z}$ $=-2.666, \mathrm{P}=0.008$; summer: $\mathrm{Z}=-2.380, \mathrm{P}=$ 0.017 ; see Fig. 4).

Table 3. Habitat parameters and their influence on PAR and 3D positions during trials and when collars were fitted to red deer in the canton of Glarus, Switzerland, during 2002-2003. +/-indicates a positive or negative association between habitat category and PAR or the proportion of 3D positions in at least one season; 'none' means that no significant association was found. Trial data from winter were data from after leaf fall (mainly November), and summer data were from before leaf fall (mainly September). Concerning the habitat parameters Proportion of conifers, Forest age class and Canopy closure, no data from collars fitted to red deer were for PAR. Concerning the habitat parameter Season, no data from trials were available from spring. For further details on data recording see section Material and methods.

\begin{tabular}{|c|c|c|c|c|c|}
\hline \multirow[b]{2}{*}{ Habitat parameter } & \multirow[b]{2}{*}{ Habitat category } & \multicolumn{2}{|c|}{ PAR } & \multicolumn{2}{|c|}{$3 \mathrm{D}$} \\
\hline & & Trial & Red deer & Trial & Red deer \\
\hline \multirow[t]{2}{*}{ Habitat type } & Forest & - & - & - & - \\
\hline & Open land & + & + & + & + \\
\hline \multirow[t]{2}{*}{ Altitude } & High & none & none & none & - \\
\hline & Low & none & none & none & + \\
\hline \multirow[t]{2}{*}{ Slope } & Plain & none & none & none & + \\
\hline & Steep & none & none & none & - \\
\hline \multirow[t]{2}{*}{ Aspect } & North & none & none & none & none \\
\hline & South & none & none & none & none \\
\hline \multirow[t]{3}{*}{ Proportion of conifers } & Conifers & none & & none & none \\
\hline & Mixed & none & & none & + \\
\hline & Deciduous & none & & none & - \\
\hline \multirow[t]{3}{*}{ Forest age class } & Young-growth & none & & + & + \\
\hline & Old-growth & none & & none & - \\
\hline & Uneven-aged & none & & - & none \\
\hline \multirow[t]{2}{*}{ Canopy closure } & Open & none & & + & + \\
\hline & Closed & none & & - & - \\
\hline \multirow[t]{3}{*}{ Season } & Winter & none & none & none & + \\
\hline & Spring & & none & & + \\
\hline & Summer & none & none & none & - \\
\hline
\end{tabular}




\section{Comparison of positions obtained from trials and from collars fitted on red deer}

Collars fitted to red deer consistently produced lower PAR than collars under comparable conditions during trials (Fig. 5). Whereas the proportion of 3D positions obtained from red deer included positions taken in both forest and open land, it was not higher than the proportion recorded in the trials that contained only positions taken in forest.

PAR was similarly affected by the parameters that were available both in the trials and for collars fitted to red deer (Table 3). The same was true in the proportion of $3 \mathrm{D}$ positions for several parameters (habitat type, exposition, forest age class and canopy closure), whereas other parameters (altitude, slope, proportion of conifers and season) showed an influence only for collars on red deer.

As a positioning attempt is started with initial information on satellite configuration from the preceding position, the length of the interval between positioning attempts may influence GPS performance (Frair et al. 2004), particularly when the period during which search for satellites takes place is short. As we had intervals that differed between trials (four minutes) and collars fitted to red deer (at least two hours), this could have been a concern in comparisons of GPS performance. However, as we allowed for 180 seconds search time, and as $>90 \%$ of the positions were obtained within $120 \mathrm{sec}-$ onds in both trials and collars fitted on red deer, differences in PAR are unlikely to be due to different time intervals between positioning attempts.

\section{Discussion}

\section{General GPS performance}

The notion that some malfunction must be expected at the current state of GPS collar technology (e.g. Merrill et al. 1998, D'Eon et al. 2002, Johnson et al. 2002, Gau et al. 2004), is consistent with our experience. Out of 18 collars fitted to red deer, 11 stopped working long before reaching the expected lifetime. We had collars from two production series, and almost all losses occurred in the later series in which technical changes had been made to improve download speed of stored data. Extensive testing of collar functioning is therefore essential before deploying GPS telemetry units. Unrelated to the handheld general testing which involved only a few of the collars, we checked the functioning of each collar in the field before deployment, and hereby detected the outright failure of one collar. However, as the ill-working collars started failing after about 2 weeks after having been fitted to the red deer, a longer test lasting for 2-4 weeks would have been required to find the problems beforehand.

Stationary locational accuracy was about twice as good in $3 \mathrm{D}$ than in $2 \mathrm{D}$ positions, a ratio also found in previous studies (e.g. Rempel et al. 1995, Moen et al. 1996, Edenius 1997, D'Eon 2002). However, because $95 \%$ of both $3 \mathrm{D}$ and $2 \mathrm{D}$ positions were within $40 \mathrm{~m}$, the locational error measured in absolute distance was quite small. This performance was similar to what has been reported from other studies using either differentially corrected GPS collars before SA was disabled, or non-differential GPS collars after SA was disabled (e.g. Moen et al. 1997, Rempel et al. 1997, Hulbert \& French 2001, Janeau et al. 2001a), but better than with equipment in non-differential GPS mode before SA was disabled (e.g. Rempel et al. 1995, Moen et al. 1996, Edenius 1997, Janeau et al. 2001a). Currently, 3D and 2D positions with a mean locational error of $\leq 15 \mathrm{~m}$ can be expected in studies conducted in regions with low altitudinal gradient or stationary GPS systems. The required accuracy will depend on the extent and the grain of the habitat used by the species in question. For large, mobile species such as red deer, the stationary locational accuracy of current GPS collars should be more than sufficient for providing the data normally needed in most habitat selection studies.

\section{Performance in rugged mountainous terrain}

Our position acquisition rates $(>90 \%$ in the trials and ca $70 \%$ with collars fitted to red deer) were similar or better than those obtained in other studies (Rodgers 2001), while overall proportion of 3D positions (20-40\%) was markedly lower, not only compared to studies from flat areas (Moen et al. 1997, Rempel \& Rodgers 1997, Di Orio et al. 2003), but also to studies from areas with more pronounced topography (Dussault et al. 1999, Rumble et al. 2001, D'Eon et al. 2002, Johnson et al. 2002). Only a few studies have previously recorded similarly low 3D proportions (e.g. Rempel et al. 1995). This means that in the strong topographic relief of the rugged Alpine landscape, even under dense vegetation, three satellites were generally available, but that the important fourth satellite was often concealed by mountains or rocks.

Because 2D positions are calculated by substituting the information from the fourth satellite with 
the altitude obtained by the last 3D position, their accuracy can be low if red deer move quickly up- or downhill between bearings. Accuracy of 2D positions taken from red deer in steep terrain should therefore be lower than from red deer in flat areas, or from stationary test systems. But we found that $>70 \%$ of the red deer positions were either 3D positions or 2D positions in which altitudinal difference to the last stored 3D position was $<150 \mathrm{~m}$. According to Moen et al. (1997), median locational error of these values can be calculated at no more than $70 \mathrm{~m}$, and $\geq 95 \%$ of the positions are within $190 \mathrm{~m}$. These values compare favourably to results obtained from traditional VHF telemetry, e.g. a Polish study of wolves Canis lupus that recorded a mean radiotracking error of $194 \mathrm{~m}$ (Theuerkauf \& Jedrzejewski 2002). Thus, GPS collars may yield positions with sufficient accuracy for many habitat selection analyses, even when they are fitted to large, mobile animals inhabiting rugged mountainous terrain.

\section{Performance under different habitat conditions}

Habitat parameters have commonly been found to affect GPS performance, both in flat and hilly terrain. Generally, a trend towards reduced PAR and proportion of $3 \mathrm{D}$ positions is apparent with increasing vegetation cover (D'Eon et al. 2002). Contrary to most other studies, we obtained high PAR values $(>90 \%)$ that were little affected by vegetation and topographic characteristics, particularly in the trials, although some differences between forest and open land still remain (see Figs. 3, 5 and Table 3). These differences were, however, much stronger in the proportion of $3 \mathrm{D}$ positions between forest and open land, a distinction also noted by Rempel et al. (1995), Moen et al. (1997) and Gamo et al. (2000). Canopy and perhaps tree stems and local topographical features apparently disrupted contact with one of the four satellites quite often, but only rarely with two or more. Proportions of 3D positions also differed inside the forest, being higher in young-growth than in old-growth or uneven-aged stands and under low canopy closure, for both trial and red deer positions. This result is consistent with findings that the mean number of satellites available tends to be negatively related to tree height (Rempel et al. 1995, Rempel \& Rodgers 1997, Dussault et al. 1999; but see Gamo et al. 2000). However, little of the variability in GPS performance in forest was explained by the habitat parameters we investigated. Differences in effects of certain other habitat parameters on GPS performance between trials and when collars were fitted to red deer, are discussed below.

A few studies have found an effect of canopy; i.e. that GPS performance was better after leaf fall than before (Dussault et al. 1999, Janeau et al. 2001b). Our trial data showed no such effect (for red deer data see below). We suggest that in our study area tree trunks and branches affected GPS performance more than leaf cover, although we cannot exclude that forests with different canopy structure (e.g. larger leaves) could produce an effect.

\section{Influence of red deer behaviour}

The collars produced higher PAR and proportions of $3 \mathrm{D}$ positions in the trials than when they were fitted to red deer, a difference that has been noted in other studies (Edenius 1997, Dussault et al. 1999, 2001) though not all previous studies on ungulates (Rempel et al. 1995, Moen et al. 1996). We recorded markedly lower PAR and proportion of 3D positions from red deer during daytime than during night, when red deer were also more active and stayed more often in open land. Since vegetation structure only affected PAR weakly in the trials, differences in PAR between day and night are unlikely to be due to habitat choice of red deer (forest vs open land), but must be related to activity and types of behaviour. Red deer were at rest mainly during daytime. The collar in a lying red deer is near ground level and contact with satellites is thus more likely to be obstructed by the animal's body, small rocks or other micro-topographical structures than when the red deer is afoot and the collar is ca $1.5 \mathrm{~m}$ above ground level. That animal behaviour such as walking or resting can influence GPS performance has also been noticed by Rumble et al. (2001).

While several habitat parameters (habitat type, forest age class and canopy closure) affected PAR and/or proportion of 3D positions in a similar manner both during the trials and when fitted to red deer, others (altitude, slope and proportion of conifers) took effect only for red deer. Contrary to the few studies that have compared GPS performance in deciduous, mixed and coniferous stands (Moen et al. 1996, Dussault et al. 1999), we found that mixed forest stands allowed for a higher proportion of 3D positions than deciduous stands. Because no such effect was apparent in the trials, we interpret the difference as a result of particular behaviours connected with stand types (e.g. resting preferably in deciduous stands and feeding in mixed stands). 
We also found that the proportion of $3 \mathrm{D}$ red deer positions was higher at lower altitudes and in the valley bottom in winter. This, however, must have simply reflected habitat choice by red deer, i.e. the intensive use of low-lying meadows which had higher nutritive value and less snow cover than meadows at higher altitudes (B. Zweifel-Schielly, pers. obs.).

Effects of season on the performance of GPS collars fitted to animals have repeatedly been found, often in the form of lower performance in summer (Edenius 1997, Moen et al. 1997, Dussault et al. 2001, Janeau et al. 2001b, Lindzey et al. 2001), which was attributed to the foliation of the trees (Dussault et al. 1999). We only found an effect of season on the proportion of $3 \mathrm{D}$ positions in deer, but none in trials. Foliage thus seems an unlikely explanation, but habitat selection by red deer could again be the reason (see also Edenius 1997). In summer, red deer spent more time in forest than in winter or spring (in summer $75 \%$ of positions were in forest vs $51 \%$ in winter and $63 \%$ in spring; B. Zweifel-Schielly, unpubl. data, based on 10 red deer).

\section{Conclusions and recommendations}

Altogether, GPS performance in our rugged mountainous study area was characterised by consistently high PAR, but a relatively low proportion of $3 \mathrm{D}$ positions compared to published studies from smoother terrain. Moreover, the proportion of 3D positions was lower in forests than in open land, but within forests different vegetation structures had only a weak influence. The high PAR probably reflects the recent progress achieved in GPS technology while the comparatively low proportion of $3 \mathrm{D}$ positions demonstrates that rugged mountainous topography can strongly reduce the probability of four satellites being available at any one time. Because altitude, which is a correlate of visible sky, did not affect the proportion of 3D positions to a large degree, we conclude that it was less the rise of the mountains itself than smaller-scale terrain structures and irregularities (e.g. boulders or cliffs) that were paramount in shielding satellites. Small topographical obstacles may also have played a role in conjunction with red deer behaviour, e.g. in animals using protection offered by tree trunks or rocks while resting. Nevertheless, positioning accuracy was quite good throughout the study because most 2D positions were sufficiently accurate.

We thus offer the following recommendations for future studies:

1) Choice of GPS or VHF telemetry: Because data loss from malfunctioning collars is still common, we recommend using GPS telemetry only if financial means, staffing and time are available to equip a sufficient number of animals with collars in order to achieve adequate sample sizes. GPS telemetry is especially suited in regions where traditional VHF telemetry is difficult to carry out, e.g. in roadless mountainous regions. It is worthwhile to test each collar individually before it is deployed, if possible for at least two weeks.

2) Accuracy of GPS telemetry: In terrain with no or small altitudinal gradients, position accuracy of GPS telemetry is within 15 metres, making studies possible that require high spatial resolution. In rugged mountainous topography, however, accuracy of GPS positions from mobile animal species realistically falls between a few metres and approximately 200 metres for about $75 \%$ of the data, and higher for the rest of the data. While such accuracy compares favourably to what can be expected from VHF telemetry, it still poses limits for the scale at which analyses (e.g. of habitat selection) may be attempted. For studies of microsite selection (e.g. of habitat elements having an extent of $<100$ $200 \mathrm{~m}$ ) by mobile species in mountainous landscapes, GPS telemetry will generally not yet be the appropriate technique.

3) Habitat-dependent bias in GPS telemetry: Since the weak influence of vegetation and topographical structure on position acquisition rate in our study probably reflects the recent technical progress in GPS telemetry, habitat-dependent bias in PAR will possibly be negligible in future and correction factors may lose their relevance. The proportion of $3 \mathrm{D}$ positions is, however, still prone to bias from vegetation and topographical characteristics in mountainous regions. We advise against the obvious solution of simply omitting less accurate positions (e.g. all 2D or, at least, inaccurate 2D) for improving statistical power in habitat selection analyses, especially when the proportion of $2 \mathrm{D}$ positions is high. Removal of 2D positions might not only affect habitat-specific proportions of positions but also result in unwarranted loss of good data, since many $2 \mathrm{D}$ positions are as accurate as $3 \mathrm{D}$ positions. For habitat selection studies, we rather recommend increasing the total number of positions so 
as to enhance chances to improve the power of the analysis (Nams 1989).

4) Red deer behaviour: Good previous knowledge of how animals move along altitudinal gradients allows time intervals between consecutive positioning attempts to be programmed so as to minimise altitudinal differences between any 2D and the last previous $3 \mathrm{D}$ position and thus, to improve positional accuracy. Because our analysis suggests that animal behaviour may affect GPS performance more strongly than vegetation or topographical parameters, the effect of different behaviour types on GPS performance needs to be investigated further in order to develop behaviourbased correction factors for habitat selection analyses or modelling purposes that are generally applicable.

Acknowledgements - we thank the canton of Glarus, Switzerland, and the Swiss Federal Office for the Environment FOEN for financial support. We are grateful to the game warden A. Schuler for his tireless help in immobilising red deer, F. Bandau, N. Hemmi, H. Schielly and J. Zweifel-Schielly for assistance in the field, R. Fankhauser for programming software to transform geographic coordinates, R. Eyholzer, R. Haller and F. Filli for useful suggestions regarding GPS telemetry, R. Graf for GIS support, B. Tona from the Seminar für Statistik of the Swiss Federal Institute of Technology Zurich and C. Hoffmann for statistical advice, all people from the research program Forest-Wildlife-Landscape of the Swiss Federal Research Institute WSL for insightful discussions, and J. Zweifel-Schielly, E. Schielly-Zaugg and two reviewers for their comments on the manuscript. We would also like to thank T. Alanko from Televilt, Sweden, for technical support.

\section{References}

Beyer, D.E. \& Haufler, J.B. 1994: Diurnal versus 24-hour sampling of habitat use. - Journal of Wildlife Management 58: 178-180.

Biggs, J.R., Bennett, K.D. \& Fresquez, P.R. 2001: Relationship between home range characteristics and the probability of obtaining successful global positioning system (GPS) collar positions for elk in New Mexico. - Western North American Naturalist 61: 213-222.

Bowman, J.L., Kochanny, C.O., Demarais, S. \& Leopold, B.D. 2000: Evaluation of a GPS collar for white-tailed deer. - Wildlife Society Bulletin 28: 141-145.

Burnham, K.P. \& Anderson, D.R. 2002: Model selection and multimodel inference: a practical information-theoretic approach. 2nd edition. - Springer-Verlag, New York, 488 pp.
D’Eon, R.G. 2003: Effects of a stationary GPS fix-rate bias on habitat-selection analyses. - Journal of Wildlife Management 67: 858-863.

D'Eon, R.G., Serrouya, R., Smith, G. \& Kochanny, C.O. 2002: GPS radiotelemetry error and bias in mountainous terrain. - Wildlife Society Bulletin 30: 430-439.

Di Orio, A.P., Callas, R. \& Schaefer, R.J. 2003: Performance of two GPS telemetry collars under different habitat conditions. - Wildlife Society Bulletin 31: 372379.

Dussault, C., Courtois, R., Ouellet, J-P. \& Huot, J. 1999: Evaluation of GPS telemetry collar performance for habitat studies in the boreal forest. - Wildlife Society Bulletin 27: 965-972.

Dussault, C., Courtois, R., Ouellet, J-P. \& Huot, J. 2001: Influence of satellite geometry and differential correction on GPS location accuracy. - Wildlife Society Bulletin 29: 171-179.

Edenius, L. 1997: Field test of a GPS location system for moose Alces alces under Scandinavian boreal conditions. - Wildlife Biology 3: 39-43.

Fielitz, U., Renner, U., Schulte, R. \& Wölfel, H. 1996: Satellitentelemetrie an Rothirschen im Harz: Eine Pilotstudie. - Zeitschrift für Jagdwissenschaft 42: 1-11. (In German).

Frair, J.L., Nielsen, S.E., Merrill, E.H., Lele, S.R., Boyce, M.S., Munro, R.H., Stenhouse, G.B. \& Beyer, H.L. 2004: Removing GPS collar bias in habitat selection studies. - Journal of Applied Ecology 41: 201-212.

Gamo, R.S., Rumble, M.A., Lindzey, F. \& Stefanich, M. 2000: GPS radio collar 3D performance as influenced by forest structure and topography. - In: Eiler, J.H., Alcorn, D.J. \& Neuman, M.R. (Eds.); Biotelemetry 15. Proceedings of the 15th International Symposium on Biotelemetry. 9-14 May 1999, Juneau, Alaska USA, pp. 464-473.

Garrott, R.A., White, G.C., Bartmann, R.M. \& Weybright, D.L. 1986: Reflected signal bias in biotelemetry triangulation systems. - Journal of Wildlife Management 50: 747-752.

Gau, R.J., Mulder, R., Ciarniello, L.M., Heard, D.C., Chetkiewicz, C.B., Boyce, M., Munro, R., Stenhouse, G., Chruszcz, B., Gibeau, M.L., Milakovic, B. \& Parker, K.L. 2004: Uncontrolled field performance of Televilt GPS-Simplex ${ }^{\mathrm{TM}}$ collars on grizzly bears in western and northern Canada. - Wildlife Society Bulletin 32: 693-701.

Girard, I., Ouellet, J-P., Courtois, R., Dussault, C. \& Breton, L. 2002: Effects of sampling effort based on GPS telemetry on home-range size estimations. - Journal of Wildlife Management 66: 1290-1300.

Haller, R., Filli, F. \& Imfeld, S. 2001: Evaluation of GPStechnology for tracking mountain ungulates: VHFtransmitter or GPS-collars? - In: Sibbald, A.M. \& Gordon, I.J. (Eds.); Tracking animals with GPS. Proceedings of the conference "Tracking animals with GPS". 
Macaulay land use research institute, 12-13 March 2001, Aberdeen, Scotland, pp. 61-66.

Hooge, P.N. \& Eichenlaub, B. 1997: Animal movement extension to Arcview. - Version 1.1. Alaska Science Center, Biological Science Office, U.S. Geological Survey, Anchorage, AK, USA.

Hosmer, D.W. \& Lemeshow, S. 2000: Applied logistic regression. 2nd edition. - John Wiley and Sons, New York, USA, $375 \mathrm{pp}$.

Hulbert, I.A.R. \& French, J. 2001: The accuracy of GPS for wildlife telemetry and habitat mapping. - Journal of Applied Ecology 38: 869-878.

Janeau, G., Adrados, C. \& Girard, I. 2001a: Is it still necessary to use GPS in differential mode since the elimination of selective availability? - In: Sibbald, A.M. \& Gordon, I.J. (Eds.); Tracking animals with GPS. Proceedings of the conference "Tracking animals with GPS". Macaulay land use research institute, 12-13 March 2001, Aberdeen, Scotland, pp. 73-75.

Janeau, G., Adrados, C., Joachim, J. \& Pepin, D. 2001b: GPS performance in a temperate forest environment. - In: Sibbald, A.M. \& Gordon, I.J. (Eds.); Tracking animals with GPS. Proceedings of the conference "Tracking animals with GPS". Macaulay land use research institute, 12-13 March 2001, Aberdeen, Scotland, pp. 69-72.

Johnson, C.J., Heard, D.C. \& Parker, K.L. 2002: Expectations and realities of GPS animal location collars: results of three years in the field. - Wildlife Biology 8: 153-159.

Licoppe, A.M. \& Lievens, J. 2001: The first tracking results from a female free-ranging red deer (Cervus elaphus L.) fitted with a GPS collar in Ardenne, Belgium. - In: Sibbald, A.M. \& Gordon, I.J. (Eds.); Tracking animals with GPS. Proceedings of the conference "Tracking animals with GPS". Macaulay land use research institute, 12-13 March 2001, Aberdeen, Scotland, pp. 25-27.

Lindzey, F., Sawyer, H., Anderson, C. \& Banulis, B. 2001: Performance of store-on-board GPS collars on elk, mule deer and mountain lions in Wyoming, USA. - In: Sibbald, A.M. \& Gordon, I.J. (Eds.); Tracking animals with GPS. Proceedings of the conference "Tracking animals with GPS". Macaulay land use research institute, 12-13 March 2001, Aberdeen, Scotland, pp. 29-31.

Marti, F., Nann, S., Walcher, J. \& Zopfi, H-J. 1997: Geschützte Pflanzen und ihre Lebensräume. - Mitteilungen der Naturforschenden Gesellschaft des Kantons Glarus 17: 1-150. (In German).

Merrill, S.B., Adams, L.G., Nelson, M.E. \& Mech, L.G. 1998: Testing releasable GPS radiocollars on wolves and white-tailed deer. - Wildlife Society Bulletin 26: 830-835.

Mills, L.S. \& Knowlton, F.F. 1989: Observer performance in known and blind radio-telemetry accuracy tests. - Journal of Wildlife Management 53: 340-342.
Moen, R., Pastor, J. \& Cohen, Y. 1997: Accuracy of GPS telemetry collar locations with differential correction. - Journal of Wildlife Management 61: 530-539.

Moen, R., Pastor, J., Cohen, Y. \& Schwartz, C.C. 1996: Effects of moose movement and habitat use on GPS collar performance. - Journal of Wildlife Management 60: 659-668.

Nams, V.O. 1989: Effects of radiotelemetry error on sample size and bias when testing for habitat selection. - Canadian Journal of Zoology 67: 1631-1636.

Rempel, R.S., Rodgers, A.R. \& Abraham, K.F. 1995: Performance of a GPS animal location system under boreal forest canopy. - Journal of Wildlife Management 59: 543-551.

Rempel, R.S. \& Rodgers, A.R. 1997: Effects of differential correction on accuracy of a GPS animal location system. - Journal of Wildlife Management 61: 525-530.

Rodgers, A.R. 2001: Tracking animals with GPS: the first 10 years. - In: Sibbald, A.M. \& Gordon, I.J. (Eds.); Tracking animals with GPS. Proceedings of the conference "Tracking animals with GPS". Macaulay land use research institute, 12-13 March 2001, Aberdeen, Scotland, pp. 1-10.

Rodgers, A.R., Rempel, R.S. \& Abraham, K.F. 1996: A GPS-based telemetry system. - Wildlife Society Bulletin 24: 559-566.

Rumble, M.A., Benkobi, L., Lindzey, F. \& Gamo, R.S. 2001: Evaluating elk habitat interactions with GPS collars. - In: Sibbald, A.M. \& Gordon, I.J. (Eds.); Tracking animals with GPS. Proceedings of the conference "Tracking animals with GPS". Macaulay land use research institute, 12-13 March 2001, Aberdeen, Scotland, pp. 11-17.

Rumble, M.A. \& Lindzey, F. 2000: Effects of forest vegetation and topography on global positioning system collars for elk. - In: Eiler, J.H., Alcorn, D.J. \& Neuman, M.R. (Eds.); Biotelemetry 15. Proceedings of the 15th International Symposium on Biotelemetry. 9-14 May 1999, Juneau, Alaska, USA, pp. 492-501.

Springer, J.T. 1979: Some sources of bias and sampling error in radio triangulation. - Journal of Wildlife Management 43: 926-935.

Theuerkauf, J. \& Jedrzejewski, W. 2002: Accuracy of radiotelemetry to estimate wolf activity and locations. - Journal of Wildlife Management 66: 859-864.

Wells, D.E., Beck, N., Delikaraoglou, D., Kleusberg, A., Krakiwsky, E.J., Lachapelle, G., Langley, R.B., Nakiboglu, M., Schwarz, K.P., Tranquilla, J.M. \& Vanicek, P. 1986: Guide to GPS positioning. - Department of Geodesy and Geomatics Engineering Lecture Note No. 58, University of New Brunswick, Fredericton, New Brunswick, Canada, 291 pp.

White, G.C. \& Garrott, R.A. 1990: Analysis of wildlife radio-tracking data. - Academic, San Diego, New York, Boston, London, Sydney, Tokyo, Toronto, 388 pp. 